\title{
Content Analysis of News Reporting about Women in the Kashmir Daily 'Greater Kashmir'
}

\section{Nilofer Khan*}

Department of Humanities, University of Kashmir, Srinagar, Jammu and Kashmir, India

\begin{abstract}
The print media including the regional newspapers are relied upon by the people as credible sources of information, education and entertainment. Various studies on print media all across the globe have shown that in the past few years there has been an improved and increased reportage of issues regarding women in the media particularly in the print. News related to women is now increasingly occupying important slot. Based on a content analysis of an English daily newspaper, Greater Kashmir, this paper examines how women's issues get portrayed. It also focuses on the coverage made by the newspaper regarding women's issues. The kinds of situation Kashmiri Women live in; the regional newspaper holds an utmost importance in preserving the data on the status of women.
\end{abstract}

Keywords: Kashmir; Social; Women; Newspaper; Language; Symbolization

\section{Introduction}

The present report is a content analysis of news items regarding women that were reported by the Greater Kashmir (Kashmir edition) from mid-2014 till end of 2016. The news items have been compiled by the Women's Studies Centre, University of Kashmir in the form of news clippings. The reason of choosing the said daily is that, Greater Kashmir is an old and widely circulated Newspaper of the valley. Throughout the years, the media have become trustworthy sources of information for individuals around the world. The public searches for information about events happening around the world and the media is the primary source. It is important to understand the tones and kinds of information that are frequently reported in the newspapers. The media plays an important role in 'creating 'a common sense of the world through its particular language and symbolization.

\section{Important Women's Issues Covered in the Greater Kashmir}

It was observed that only three major stories of women get a chance to be reported. One of the most widely covered subjects by Greater Kashmir is suicide committed/attempted by women in Jammu and Kashmir. The Second is about rape and molestation cases. Third being the physical assaults in public including murder and acid attacks. It is clear then that most of the representation the newspapers bring to the readers is that of a woman who is being victimized. The kinds of situation Kashmiri women live in; the regional newspaper holds an utmost importance in preserving the data on the status of women. The news clippings have revealed that there were more than 81 women who either committed suicide or made serious attempts to end their lives. There were 16 cases of sexual crimes against women including rapes and molestations. There was one case of acid attack, and there were 7 cases of women being murdered.

\section{Suicides}

Suicide is a serious public health problem that can have lasting harmful effects on individuals, families, and communities. Most of the women who commit suicides belong to above 25 years of age group; an age when an individual is considered to be mature and responsible. Most of them are married having children. Figure 1 illustrates that $66 \%$ of women above 25 years of age have resorted to this serious offense against their own-selves. 22\% belonged to $18-25$ years age and $6 \%$ were of below 18 years of age which is a cause of great concern. From the frequent reporting of suicides in this particular Newspaper, it is clear that suicides are happening rampantly in Kashmir, causes of which are yet to be traced. Based on the total number of news reports on suicides, it is observed that Kupwara has the highest number of suicide cases in the said period, followed by Anantnag and Baramulla. Figure 2 illustrates Budgam, Kulgam, Srinagar, Bandipora and Pulwama are among other districts where suicides have become more widespread. However, as is noticed from many such reports, there is an apprehension that these suicides were inflicted on women by their in-laws. Most of the suicides committed by women are mostly the result of prolonged domestic violence abuses, The news reports also recorded the claims of their families who believed the suicide were actually murders planned by the in-laws, mainly the husbands on account of domestic strife. In large number of cases, it has been reported that these women were harassed by the in-laws for not been able to give enough dowry [1]. There were

\section{Suicide Trends Among Women (Age Wise)}

above 25 abelow 18 a between 18-25

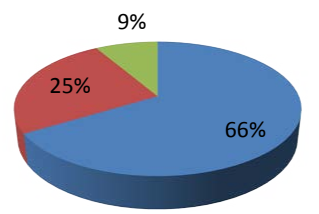

Figure 1: Suicide trending among women.

${ }^{*}$ Corresponding author: Nilofer K, Department of Humanities, University of Kashmir, Srinagar, Jammu and Kashmir, India, Tel + 91 (194) 227 2096; E-mail: shaziamalik1366@gmail.com

Received October 06, 2017; Accepted October 13, 2017; Published October 21 2017

Citation: Khan N (2017) Content Analysis of News Reporting about Women in the Kashmir Daily 'Greater Kashmir'. Arts Social Sci J 8: 309. doi: 10.4172/21516200.1000309

Copyright: (c) 2017 Khan N. This is an open-access article distributed under the terms of the Creative Commons Attribution License, which permits unrestricted use, distribution, and reproduction in any medium, provided the original author and source are credited. 


\section{Number of Suicides, Commited or Attempted between mid 2014}

to 2016 end.

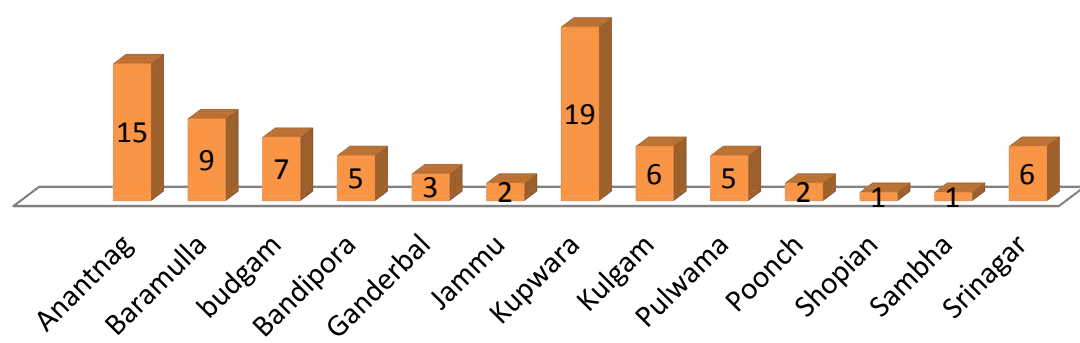

Figure 2: Number of suicides committed or Attempted between mid-2014 to 2016 end.

\section{Rapes and Molestation}

rural u urban

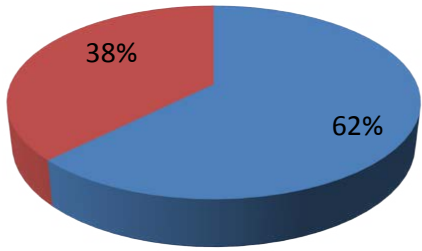

Figure 3: Rapes and molestation.

about 8 cases of women burning themselves in presence of their in laws. Women also resort to end their lives to avoid their character assassinations. In Kupwara, a local youth was blackmailing a teenager girl and was uploading her pictures on Facebook. Unable to bear the trauma, she committed suicide. Since girls now tend to find more meaning to their lives through educating themselves, some aspiring girl students have committed suicide owing to their failure in examinations (Figure 2). The incidences of suicides appear more in rural areas as compared to urban areas. Figure 3 depicts that $73 \%$ of such cases take place in rural settings which should be taken into consideration while building policy measures to intervene in the rising tendencies of suicides in Kashmir. As we know there is a stigma attached to such incidents happening in a family, there is every possibility that due to availability of more private health services in urban areas, many cases are hushed off, before getting media attention and hence are not recorded. It is important to mention here that Greater Kashmir has a separate edition for Jammu region and therefore most of the cases pertaining to Jammu region are not reported by the Kashmir edition.

\section{Rapes and Molestations}

From the news reports, reported by Greater Kashmir, between mid-2014 till end 2016, it has been noticed that Kashmir is witnessing an increase in the sexual assaults against women in public places. A dentist in his clinic in Maisuma Srinagar and a Lab Technician at his private lab in Pulwama, were held for sexually assaulting minor girls both of them (victims) revealed the incident to their families only after some days for the fear of not being trusted. There is a possibility that a higher number of such assaults are taking place but are not reported by the girls and their families. It also seems that girls are prone to the sexual assaults everywhere. An imam was also held for molesting a girl, while she had gone to learn Quran from him (Figure 3).

There were 10 cases pertaining to Kidnapping, rapes and molestation of girls from rural areas where as there were 6 such cases in urban areas. Rapes and molestations are a manifestation of power. A person from Territorial Army raped a woman and was caught hold by the neighbours in district Kupwara In yet another case, in Udhampur, an Army man was found beating and stripping a woman in full public view.

\section{Murders and Other Crimes}

Very often woman become victims of the masculine authority to an extent that their lives as human beings are least valued. Masculinity which is based on the notion of superiority over females, tend to subjugate women by several means. Sometimes this phenomenon takes the form of grave offenses like murder and acid attacks. A 15 year old girl was strangulated by her own cousin Bijbehara, after she rejected the advances of her cousin, who had also wanted that she quits her coaching classes. The hapless parents got the news from social media. In a similar incident in Budgam, a girl was strangulated by her ex-lover on getting engaged with some other person. In similar grave incident, where a boy took an extreme step owing to his vengeful tiff, a 21 year old law student was injured in an acid attack on the pretext that she dared to spur the advances of the accused in Shopian a woman was rescued by neighbours while she was ablaze by the in-laws. After filing a complaint against in-laws a woman from Doda was murdered in a day. It also appears that women remain the victims of domestic violence all through their lives. An elderly (60 year old) woman was beaten to death by her husband following a domestic strife in Tangdhar Kupwara.

\section{Women Underrepresented}

There is a pronounced tendency across the whole of the media for women to disproportionately appear in passive roles - as victims of crime, instead of actually doing something. This scenario also, however, reflects a wider culture. In the Greater Kashmir women are more likely to be featured in stories about murder, sexual abuses or domestic violence than in stories about their professional abilities or expertise. It is also a matter of concern that women are not even interviewed on critical issues regarding women or other social issues. Women largely remain excluded in their representations in terms of their active participations in several government, non-government programmes, researches, art, literature and sports. Women's perspectives on issues of political, economic and social importance have been fully ignored. 
While reporting the issues of crimes against women, the news reports lack in-depth research and follow ups. Owing to the lack of sensitivity, the age, and residential particulars are often not complete in cases of women being raped, burnt or murdered. Also the newspaper gives such items the marginalized and little spaces. Even the murders and gang rape stories do not qualify to get published in the front pages. It is matter of great concern that female journalists do not file such stories very often. It is mainly male journalists who cover and file stories on crimes against women.

\section{Conclusion}

While many factors are known to influence public perceptions about issues on women, the present paper has examined the role of news. There remain gaps in our knowledge with more research needed as to the impact of news coverage on public understandings, attitudes and behaivours and how to best craft mediated messages to more effectively promote positive social change. More and more female journalists should be encouraged to cover the news reports on crimes against women. By doing this, it is expected that the coverage will be sensitive and compassionate, without making it sensational. Women's say needs to be documented properly on the backgrounds of crimes done within the premises of workplaces or family/community. The Greater Kashmir in particular and the other dailies in general need to encourage coverage of wide range of issues concerning women. They also need to increase printing spaces for women's issues and their successful stories.

\section{References}

1. Alat $Z$ (2006) News coverage of violence against women: The Turkish case Feminist Media Studies 6: 296 